\title{
Stigma and mental health: The curious case of COVID-19
}

\author{
Connie J. Snider ${ }^{1}$
}

Maureen P. Flaherty ${ }^{2}$

Alzheimer Society of Saskatchewan, Saskatoon Resource Centre, Saskatoon, Saskatchewan, Canada' University of Manitoba, Winnipeg, Canada ${ }^{2}$

\begin{abstract}
Introduction: This article considers the impact of COVID-19 on stigma and mental health across the life spectrum and the ways that people access services.

Purpose: To explore the ways that a pandemic (COVID-19) has changed/shifted the relationship between mental illness or mental ill health and stigma across the life spectrum and call to refocus resources on sustainable healthy societies, building cultures of peace.

Methodology: A literature search was employed, combined with informal interviews and observation.

Results and Discussion: On the one hand, the pandemic has opened public discussion of mental health challenges such as anxiety and depression, reducing some of the stigma attached as the experience is more common amongst people who hove not previously declared mental health challenges. On the other hand, people previously experiencing mental ill health hove mostly had that health challenge exacerbated by the pandemic. With fewer resources available, and changes in service delivery to largely on-line resources, the reduction in stigma has not meant better mental health care and services, but rather further marginalized some of the population. Cultures of peace are inclusive and provide space for full growth of all citizens, in contrast to reactive approaches now more readily applied. Mental health services are a basic right for all people and should be considered as such in all planned health strategies.
\end{abstract}

Limitations: The article focuses on literature review, anecdotal and observation and is focused over a short term, in North America. It is a preliminary study.

Strengths: As a preliminary study, the article highlights an emergent and present dilemma. It also highlights the need for a much more holistic, global approach to mental health and wellbeing across the lifespan.

Conclusion: While there are calls for national strategies for mental health services and services for people with dementia, in particular, there is still a need to take a more holistic approach to mental health as part of a whole health strategy to support human dignity and inclusion across the lifespan

Keywords

mental health, mental illness, dementia, stigma, COVID-19, peacebuilding

Address for correspondence:

Connie J. Snider, First Link Coordinator, Alzheimer Society of Saskatchewan, Saskatoon Resource Centre, Saskatoon, Saskatchewan, Canada e-mail: csnider@alzheimer.sk.ca This work is licensed under a Creative Commons Attribution-

NonCommercial 4.0 International License (CC BY-NC 4.0).

\section{(c) (7) (8)}

(C) Copyright: Snider, Flaherty, 2020

Submitted for publication: 14 June 2020 Received: 14 June 2020 Accepted for publication: 5 October 2020

Licensee NDSAN (MFC- Coordinator of the NDSAN), Italy DOl:: http://doi.org/10.32437/mhgcj.v3i1.89 


\section{Introduction}

COVID-19 continues to greatly impact the ways ordinary citizens lead our lives. With the shutdown of businesses, educational establishments of all kinds, services, and almost any kind of direct human contact outside of family 'bubbles', there has been an increase in the reported incidence of anxiety and depression in particular. There has also been a change in the ways that anxiety and depression are talked about. Mental ill health in general, has become a more acceptable topic of discussion on the interpersonal, community and even the international level. This article shares a preliminary exploration of the ways that the pandemic (COVID-19) has changed/shifted the relationship between mental illness or mental ill health and stigma for some and the various ramifications of same. The article begins with an introduction to COVID-19, the pandemic that has changed lives and caused many deaths around the world. We move to a discussion of mental health and the stigma that often accompanies it. We then explore the change in the relationship between mental health and stigma in the first six months of COVID-19 and consider the shifts to accessing services for those living with mental health challenges during these times. We conclude by considering ways that the challenges of this pandemic may be utilized for improvement in approaches to mental health and wellbeing (health promotion, services, service access, service promotion and attitudinal change). This article is further to an introductory article on mental health and peacebuilding in Canada and Ukraine (Flaherty, Sikorski, Hayduk, Klos, \& Vus, 2020).

\section{Purpose}

This article explores the ways that a pandemic (COVID-19) has changed/shifted the relationship between mental illness or mental ill health and stigma and the various ramifications, considering mental health and illness in general and dementia in particular as these are the areas of our special interest. We note that this is a preliminary discussion in the midst of a pandemic that has been experienced for six months for those of us who live in North America, but several more months in different areas of the globe.

\section{Methodology}

A literature search was employed, combined with informal interviews and observation.

\section{Results and Discussion}

\section{COVID - 19}

COVID-19 is the name attributed to the novelcorona virus first reported to officials in Wuhan City, China in December in 2019. The virus or infections disease, first identified as connected to a food market in Wuhan City spread very quickly to other countries. Officially known as SARS-CoV-2, the disease was identified as such in early January 2020 and this disease has now been found in all corners of the world (World Health Organization, 2020). At the time of writing, autumn 2020, there have been almost 929 thousand deaths out of almost 29.3 million cases worldwide (BBC News, 2020). In response to the speed the disease has spread, many countries shut down work from offices, and closed all inperson business by mid-March of this year. While this is a global phenomenon which stopped international travel for months and halted much in-person communication for that same time period and longer, many businesses have not reopened in Canada at the time of writing. When they do open, it is with strict protocols about wearing masks, sanitizing areas, and restricting access (Government of Ontario, 2020) .

Both the responses to and the impact of the virus have varied across sectors, often related to a number of the social determinants of health, including Indigeneity, food security and insecurity and socio-economic resources in general (Statistics Canada, 2020).

\section{Mental Health}

The Canadian Association of Social Workers' (n.d.) provides a helpful definition of mental health:

Mental health is the capacity of the individual, the group and the environment to interact with one another in ways that promote subjective wellbeing, the optimal development and use of mental abilities (cognitive, affective and relational), the achievement of individual and collective goals with justice and the attainment and preservation of conditions of fundamental equality.

Indeed, Helen Verdeli (2016) reflects on the WHO's 2001 statistics related to the challenges to mental health and wellness, noting that one in four people around the world will "experience at some point in their lives a mental or neurological condition" (Verdeli, 2016, p. 761). Verdeli is clear that "cultural norms, beliefs and attitudes can either exacerbate stigma and instill shame or serve as protective factors by establishing clear social roles and community structure" (p. 765) to 
support good mental health and assist both individuals and communities to reach their full potentials.

Indeed, while sometimes seen as controversial and stigmatizing (DeFehr, 2020), the diagnosing of mental ill health, often known as a "disorder" has become critical in today's medical approach to health for individuals to access many of the services that can help them live well, particularly when dealing with what are considered to be "major mental illnesses", or serious mental illness (SMI) - "mental, behavioral or emotional disorder[s] resulting in serious functional impairment, which substantially interferes with or limits one's major life activities" (National Institute of Mental Health, 2019, para 4). Even when symptoms are accurately reported to medical practitioners, many people experiencing mental ill health receive inadequate care. In Canada for example, family doctors are often overworked and overwhelmed with patients, and as a result, many people are left without a family doctor (Canadian News Facts, 2001; Dinshaw, 2016). This is troubling because the majority of individuals who seek professional help for their mental health turn to someone they know and trust, their family doctor (Statistics Canada, 2017) and it is often there a referral is made to more specialized services, if they are available and deemed necessary. We remember that these are not preventative services, but rather responding often to health challenges that will have already impaired an individual's ability to function in society.

If one is fortunate enough to access a suitable mental health care individual or service, there are still challenges to accessing appropriate treatment. A study with users of mental health services and psychiatrists (Gunasekara, Patterson, \& James, 2017) revealed that it was not uncommon for patients to feel as if they were being judged in the process of accessing treatment, and that their humanity was reduced to a diagnosis.

In Canada, out of a population of just over 35 million people (Statistics Canada, 2017) over the course of a year an estimated 4.9 million Canadians over the age of 15 required professional help for their mental health (Statistics Canada, 2017). Many of those people were unsatisfied with the quality of care they received more than a third felt that they received only adequate assistance (Statistics Canada, 2017). Importantly, these numbers record only those who actually received service and not the many suffering who have not yet sought or received help. An estimated 564,000 Canadians live with Alzheimer's disease and other dementias, yet people with the illness often feel excluded or treated differently (Alzheimer Society, n.d.).

\section{Mental health and stigma}

One of the greatest challenges facing people experiencing mental health issues is stigma, described by Goffman (1963) as the social exclusion and reduction of an individual based on an undesirable trait such as is found in the negative views associated with those who dealing with mental illness (Vogel, HeimerdingerEdwards, Hammer, \& Hubbar, 2011). Numerous researchers have noted the harmful impacts of social stigma on those with mental health conditions (see Chronister, Chou, \& Liao, 2013; Clement, et al., 2015; Corrigan, 2000).

Stigma surrounding mental health is reproduced daily, found often in the language used when discussing mental health with people displaying mental illness or seeking treatment called "crazy," or "not being all there", as if because of their mental health they are missing something (Larson, 2008; Corrigan, 2000). This kind of hurtful language is the projection of attitudes about mental health and illness (Marion, Whitty-Rogers, \& Panagopoulos, 2013). The attitudes and language are found not only in the general population but also, at times, amongst health care professionals themselves (Hankir \& Zaman, 2015; Marion, Whitty-Rogers, \& Panagopoulos, 2013). While we have long talked about stigma related to variety of illnesses such as schizophrenia and bi-polar disorder, less often do we acknowledge that this stigma extends to people living with dementia (Alzheimer Society, n.d.) and even to the their caregivers and others associated with them (Werner \& Heinik, 2008). It can be argued that stigma is the greatest barrier to accessing and using mental health services (Sartorius, 2007) with many people not bothering to seek help because they feel marginalized by any kind of diagnosis (Gearing, et al., 2015; Corrigan P. , 2000; Vogel, Heimerdinger-Edwards, Hammer, \& Hubbar, 2011 ).

In addition to exposure to stigma from others, people experiencing mental illness may also contribute to the stigma themselves. Internalized stigma, or self-stigma (Vogel, HeimerdingerEdwards, Hammer, \& Hubbard, 2011) may diminish one's self-esteem and confidence (Corrigan, 2004), impacting how one behaves in the world and whether and how one seeks help when struggling. Despite the educational campaigns to reduce prejudice and increase understanding of the often-genetic aspects to mental illness, stigma remains strong, often based on people's personal interactions with

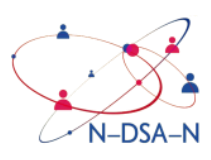


mental health challenges and what they see portrayed in the media, which often focuses on tragic events (Committee on the science of Changing Behavioral Health Social Norms; Board on Behavioral, Cognitive and Sensory Sciences; Division of Behavioral and Social Sciences and Education; National Academies of Science, Engieering, and Medicine, 2016). Sigma is fundamentally a social phenomenon rooted in social relationships and shaped by the culture and structure of society.

\section{COVID and stigma}

With the development of COVID -19 and the increased challenges to people's health and wellbeing, there has been a noticeable shift in the way people talk about mental health. Anecdotally, and in our local media (Morton, 2020; Crawford, 2020) and health services publications (e.g. CAMH, 2020), we can attest to an increased discussion of mental health and wellness as well as challenges to these since the start of COVID-19. In other words, some of the stigma has been reduced - at least for now. Anxiety and depression, as part and parcel of life in uncertain times, are now much more a part of everyday discourse. This is reflected locally and internationally. As early as the end of May, 2020 Statistics Canada (2020) reported the United Nations' concern about the adverse effects of social isolation on the population's mental health. People speak about exacerbating causes: being much more housebound, unable to access regular activities used to maintain social connection (family gatherings, clubs, concerts, dining out) enrichment (theatre, cinema) and deal with stress (physical activity, team sports, attending fitness venues). However, while this new isolation has become a much more "shared" phenomenon, experienced by most of the world to some extent, the impact of these shared experiences has been mitigated or exacerbated to some extent dependent upon economic status, living conditions, access to resources and even race, as these factors often become intertwined.

\section{Covid-19 and access to mental health resources}

Despite what appears to be an increased focus on the need for better mental health services and resources and more focus on normalizing this need (CAMH, 2020) these resources have actually become less accessible during times of COVID-19, and we wonder about the long term impact of the disappearance of these resources. The availability of many resources has drastically changed. Like many other individual day and group services, community based, subsidized programs are not available for people with dementia due to COVID restrictions - no Adult Day Programs, no in-facility respite, less in home respite and less available Home Care programs and services. This has put an increased stress on the primary caregiver who used to rely on these programs to provide respite to the caregiver. People with dementia have died at a disproportionately high rate during Covid-19 (Livingston, et al., 2020), their physical and mental health needs further challenged by decrease in supports for themselves and their caregivers. Further, with more people in need of mental health services, fewer are accessing the resources that are there (Canadian Mental Health Association, 2020), with increased protocols such as mask-wearing, reduced walk-in services, etc., some turning to drugs and alcohol to cope with their challenges, increasing co-morbidity of substance abuse and mental health challenges (Chiappini, Guirguis, John, Corkery, \& Schifano, 2020). This has a domino effect, increasing the rate of homelessness in our locales as people are not managing to pay rent.

Indeed, many in-person services are no longer available, or if they are, only on a sporadic basis. If not able to avail themselves of services in person, individuals may be able to have a medical or counselling appointment on line something not accessible to those who are not familiar with computers, or don't have one, and perhaps do not even have a home. Someone with dementia, in particular may have difficulty accessing online services. With a lack of understanding of how to connect, or use the technology, services are not just a phone call away! Organizations such as the Alzheimer Societies across Canada have had to learn how to deliver programs that were in person, to online services assisting people to get connected. Far fewer programs are available to people and when they are, they may not be just what people need. Anecdotally, one client shared her experience of receiving a diagnosis of Alzheimer disease from a neurologist over the phone with no follow up provided. Her story joins many who have identifiable illnesses and no available resources.

\section{Conclusions}

COVID-19 has highlighted the need for a different and expanded understanding of mental health and mental health services. This is a multifaceted, complex issue. First, increased attention is being paid to mental health and wellness 
during Covid-19 as people who have not commented previously talk about their anxiety and depression, perhaps newly experienced, and exacerbated for those with pre-existing conditions. Second, with the anxious uncertainty and fewer material resources that accompany COVID for many, there is a greater need for services that would assist people experiencing mental health challenges. Third, despite the reality that more services are needed, many of the resources that once were available have disappeared, at least temporarily. Fourth, people have become more creative in the ways that they offer and utilize resources, using zoom and telemedicine to share services. However, these resources are out of reach for many with cognitive challenges or any kind of financial and/or housing instability. In short, with fewer resources available, and changes in service delivery to largely on-line resources, the reduction in stigma has not meant better mental health care and services, but rather further marginalized some of the population.

The Canadian Association for Mental Health notes concerns about the impact of COVID-19 on the mental health of citizens and calls for a long- term national strategy to improve mental health care related to the pandemic and beyond (Canadian Association for Mental Health, 2020). This is not the first time such a strategy has been solicited; however, with the increased acknowledgement of the impact of the COVID19 associated stressors on mental health for the general population, there has been much more social discourse about mental health. Clearly, an international strategy with a focus on prevention and good mental health as a part of our daily discourse is needed. It is beyond time to return as a global village to focus on the social determinants of mental health outlined by the World Health Organization in 2014 (World Health Organization, 2014). The WHO notes, "Mental health is integral to this conceptualization of wellbeing, because it enables people to do and be the things they have reason to value. Conversely, being and doing things one has reason to value contributes to mental health." (WHO, 2014, p. 13). This is not a luxury; it is about agency and empowerment of citizens - a necessity for our world's survival.

\section{Conflict of interest}

The authors declare that they have no conflict of interest.

\section{References}

Alzheimer Society. (n.d.). Stigma against dementia. Retrieved October 2020, from Alzheimer Society: https://alzheimer.ca/en/aboutdementia/stigma-against-dementia

BBC News. (2020, September 15). Coronavirus: Six months after pandemic declared, where are the gobal hotspots? Retrieved from BBC News: https://www.bbc.com/news/world-51235105

CAMH. (2020). Mental health and the COVID-19 pandemic. Retrieved 09 2020, from Canadian Association of Mental Health: https://www.camh.ca/en/health-info/mentalhealth-and-covid-19

Canadian Association for Mental Health. (2020, July). Mental health and Covid-19 and beyone: $\mathrm{CAMH}$ Policy Advice. Retrieved October 2020, from Canadian Association for Mental Health: https://www.camh.ca//media/files/pdfs---public-policysubmissions/covid-and-mh-policy-paperpdf.pdf

Canadian Mental Health Association. (2020, 05 14). New data says fewer Ontarians are seeking mental health supports during covid19... Retrieved from Canadian Mental Health Association: https://ottawa.cmha.ca/fewerontarians-seeking-mental-health-supportsduring-covid-19/

Canadian News Facts. (2001). Family doctor shortage critical (in Canada). Canadian Periodicals Index Quarterly, 6323.

Chiappini, S., Guirguis, A., John, A., Corkery, J., \& Schifano, F. (2020, July 29). Covid-19: The hidden impact on mental health and drug addiction. Retrieved 10 2020, from Frontiers in Psychiatry:

https://www. frontiersin.org/articles/10.3389/fpsyt $.2020 .00767 / f u l l$.

Committee on the Science of Changing Behavioral Health Social Norms; Board on Behavioral, Cognitive and Sensory Sciences; Division of Behavioral and Social Sciences and Education; National Academies of Science, Engieering, and Medicine. (2016). Ending discrimination against people with mental and substance use disorders: Th evidence for stigma change. Washington, DC: National Academies Press (US).

Corrigan, P. (2000). Mental Health Stigma as Social Attribution: Implications for Research Methods and Attitude Change. Clinical Psychology: Science and Practice, 7(1), 48-67.

Crawford, B. (2020, 09 21). It affects nearly everyone: Anxiety, depression soar during COVID-19 pandemic, research at The Royals reveals. Retrieved 09 2020, from The Ottawa Citizen: https://ottawacitizen.com/news/local- 
news/it-affects-nearly-everyone-anxietydepression-soar-during-covid-19-pandemicresearch-at-the-royal-reveals

DeFehr, J. (2020). Mental disorder diagnosis as colonial place-naming: Contesting the practices of implied consent. In J. Charlton, $\mathrm{H}$. Michell, \& S. (. Acoose, Decolonizing mental health: Embracing indigenous multidimensional balance (p. Chapter 18). Vernon, B.C.: JCharlton Publishing.

Dinshaw, F. (2016). Physicians say new contract doesn't address mental health training, doctor shortage. Chronicle - Herald, A5. Retrieved from Chronicle - Herald.

Flaherty, M., Sikorski, E., Hayduk, N., Klos, L., \& Vus, V. (2020). Peacework and mental health: From individual pathology to community responsibility. Intervention: Journal of mental health and psychosocial support in conflict affected areas, 18(1), 18-28.

Gearing, R., MacKenzie, M., Ibrahim, R., Brewer, K., Batayneh, J., \& Schwalbe, C. (2015). Stigma and Mental Health Treatment of Adolescents with Depression in Jordan. Community Mental Health Journal, 51(1), 111 117.

Government of Canada. (2018, 08 19). A demential strategy for Canada: Together we aspire: In brief. Retrieved 10 2020, from Government of Canada:

https://www.canada.ca/en/publichealth/services/publications/diseasesconditions/dementia-strategy-brief.html

Government of Ontario. (2020, 04/08). Reopening Ontario: Frequently asked questions about Stage 1. Retrieved from Government of Ontario: https://www.ontario.ca/page/reopeningontario-frequently-asked-questions-aboutstage- 1

Gunasekara, I., Patterson, S., \& James, S. (2017). What makes an excellent mental health doctor?' A response integrating the experiences and views of service users with critical reflections of psychiatrists. Health \& Social Care in the Community, 25(6), 17521762.

Larson, G. (2008). Anti-oppressive Practice in Mental Health. Journal of Progressive Human Services, 19(1), 39-54.

Livingston, G., Huntley, J., Sommerlad, A., Arenes, D., Ballard, C., \& Banerjee, S. e. $(2020$, August). Dementia prevention, intervention and care: 2020. The Lancet, 396(10248), 413-316.

Morton, S. (2020, 09 21). Mental health Monday: Tips for keeping up during the pandemic. Retrieved from Global News: https://globalnews.ca/news/7348466/mentalhealth-tips-coronavirus-covid-19-pandemicl

National Institute of Mental Health. (2019, 02). Mental health information: Mental illness. Retrieved 09 2020, from National Institute of Mental

Health: https://www.nimh.nih.gov/health/statistics/ment al-illness.shtml

Sartorius, N. (2007). Stigma and Mental Health. The Lancet, 370(9590), 810-811.

Sheikh, I. (2016, May 5). Why Ontarians in mental health crisis turn to hospital emergency rooms. Retrieved from TVO: https://tvo.org/article/current-affairs/sharedvalues/why-ontarians-in-mental-health-crisisturn-to-hospital-emergency-rooms

Statistics Canada. (2017, May 11). Accessing mental health care in Canada. Retrieved from Statistics Canada: http://www.statcan.gc.ca/pub/1 1-627-m/1 1 627-m2017019-eng.htm

Statistics Canada. (2017, 03 31). Canada at a glance 2017: Population. Retrieved 03 28, 2018, from Statistics Canada: https://www.statcan.gc.ca/pub/12581x/2017000/pop-eng

Statistics Canada. (2020, August 7). Covid-19: A data perspective. Retrieved September 2020, from Statistics Canada: https://www.statcan.gc.ca/eng/covid19?HPA= 1

The Daily: Canada's mental health duirng the COVID-19 pandemic. (2020, 05 27). Retrieved 09 2020, from Statistics Canada: https://www150.statcan.gc.ca/n1/dailyquotidien/200527/da200527b-eng.htm

Verdeli, H. (2016). Global mental health: An introduction. Retrieved from DOI: 10.1002.jclp. 22357

Vogel, D., Heimerdinger-Edwards, S., Hammer, J., \& Hubbar, A. (2011). 'Boys don't cry': examination of the links between endorsement of masculine norms, self-stigma, and help-seeking attitudes for men from diverse backgrounds. Journal of Counseling Psychology, 58, 368-382.

Werner, P., \& Heinik, J. (2008). Stigma by association and Alzheimer's disease. Aging and mental health, 12(1), 92-99 https://doi.org/10.1080/12607860701616325

World Health Organization. (2014). Social Determinants of Mental Health. Retrieved October 2020, from World Health Organization:

https://apps. who.int/iris/bitstream/handle/1066 5/1 12828/9789241506809 eng.pdf;'jsessionid $=6958 \mathrm{C} 382 \mathrm{AB} 67177 \mathrm{~B} 3 \mathrm{~B} 43887159306145$ ? se quence $=1$

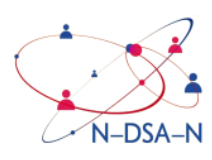


World Health Organization. (2020, 04 23). Coronavirus disease 2019 (COVID-19) Situation Report - 94. Retrieved from World Health Organization: https://www.who.int/docs/defaultsource/coronaviruse/situationreports/20200423-sitrep-94-covid-19.pdf 